\title{
Validation of core medical knowledge by postgraduates and specialists
}

\author{
Franciska Koens, Jany J D J M Rademakers \& Olle Th J Ten Cate
}

BACKGROUND Curriculum constructors and teachers must decide on the content and level of objectives and materials included in the medical curriculum. At University Medical Centre Utrecht it was decided to test relatively detailed knowledge at a regular level in study blocks and to design a progress test aimed at the medical core knowledge that every graduating doctor should possess. This study was conducted to validate the level of knowledge tested in this progress test.

AIM We designed a questionnaire to investigate whether postgraduate trainees and experienced specialists agree with item writers on what is required core knowledge.

METHODS Postgraduates and specialists received a questionnaire with 80 items designed to test core knowledge. Respondents were asked to indicate to what extent the items actually represented the core knowledge required of a recently graduated medical student.

RESULTS Of the clinical questions, $82.4 \%$ were judged to reflect core knowledge, whereas only $42.4 \%$ of the basic science questions were judged to reflect core knowledge. There was a strikingly high correlation on the mean judgements per item of postgraduate trainees versus medical specialists $(r=0.975)$.

CONCLUSION Many items, written to reflect core knowledge, appear to be judged by postgraduates and clinicians as pertaining to non-core knowledge.

University Medical Centre Utrecht, Onderwijsinstituut Geneeskunde, Utrecht, the Netherlands

Correspondence: Franciska Koens, VU University Medical Center, Medical Education Department, MF-room D237, P.O. Box 7057, 1007 MB Amsterdam, The Netherlands. Tel: 003120444 5671; Fax: 003120444 8427
Postgraduate trainees appear to be as capable as experienced specialists of making judgements regarding core knowledge. Fewer basic science items are regarded as core knowledge than clinical items. This may suggest that, specifically, basic science teachers do not agree with physicians on what is to be considered medical core knowledge for graduating doctors.

KEYWORDS humans; clinical competence/ *standards; physicians/*standards; *specialism; consultants.

Medical Education 2005; 39: 911-917

doi:10.1111/j.1365-2929.2005.02246.x

\section{INTRODUCTION}

Curriculum constructors and individual teachers are frequently faced with questions pertaining to curricular content. Decisions on what to include in the teaching programme, and to what depth, are not only guided by formal educational objectives that must be reached. To a large extent, individual expert teachers must personally determine which topics are dealt with and in what detail. They are guided by experience in daily practice, knowledge of the literature, consensus with colleagues in the field and personal interest and experience. In the last decades, national efforts in several countries have led to the establishment of broad objectives for undergraduate medical training and, more recently, also for postgraduate training. ${ }^{1-6}$ These objectives have been helpful in terms of designing curricula, but ultimately do not determine the depth of required knowledge at item level, simply because they cannot be written in sufficient detail. Specifically, in countries without national medical examinations, curriculum committees, programme directors and individual teachers must decide on the educational content. 


\section{Overview}

What is already known on this subject

Clinical teachers and basic science teachers seem to hold different opinions about the core knowledge required of graduating medical students, but studies that have investigated this do not support this conjecture.

\section{What this study adds}

We found experienced clinicians and postgraduate clinical trainees consider many progress test items, written to assess core knowledge at graduation, too detailed or too difficult, particularly those written by basic science teachers. Clinicians and postgraduates show very high agreement in their judgements at item level.

\section{Suggestions for further research}

Discrepancies between clinical and basic science teachers ask for explanation and methods should be developed to identify the required depth of knowledge.

In much the same way, medical core knowledge is not very well defined. The idea of dividing the educational programme into a 'core curriculum' and electives - or 'special study modules' - has been recommended by the General Medical Council in the UK and similar authorities elsewhere. ${ }^{2,7}$ Core knowledge has been defined as 'key aspects of all subjects or disciplines that all doctors should have [mastered], essential competencies that result in incompetent doctors when lacking, requiring high standards of mastery'. The World Federation of Medical Education aims to establish standards for minimum requirements in basic medical education. ${ }^{9}$ However, again medical core knowledge has not specifically been defined.

It is known that medical teachers differ in their views of what constitutes essential knowledge for medical graduates. Clinicians and basic scientists may agree on what topics should be included in a medical curriculum, but appear to differ in their opinions on the required depth of knowledge. ${ }^{10,11}$ Recently graduated medical students may differ in their opinions from experienced doctors, having recently been exposed to the knowledge of academic expert teachers. Conversely, they may not yet have acquired the broad overview necessary to judge the real relevance of particular knowledge for daily practice. Using an Angoff procedure to determine a pass or fail standard in a progress test, Verhoeven et al. found that recently graduated medical students produced more lenient standards of required knowledge than item writers. ${ }^{12}$ Harris et al. found a correlation between postgraduates' performance on a pre-clerkship and their ratings of relevancy of the items to medical practice. ${ }^{13}$ If it is true that basic scientists consider more detailed knowledge to be relevant for graduating doctors than clinicians do, ${ }^{11}$ then it is also likely that teachers consider their own specialty to be relatively more important than other areas of the medical field.

We decided to investigate whether core knowledge, as determined by basic science and clinical teachers (item writers) in their own fields, would be considered as such by recently graduated medical doctors and experienced medical specialists in a wide range of specialties. Postgraduate trainees were considered to be graduated medical students who were in training to become medical specialists. Experienced specialists were those specialists who were part of senior staff and who taught in the curriculum. We did not have a preconceived hypothesis, but the results of Verhoeven et al.'s study might indicate that postgraduates tend to think that less core knowledge should be required than specialists consider necessary. In our study, medical core knowledge was defined as general medical knowledge in a wide range of content areas, clinically relevant for almost every doctor and therefore to be mastered and known by heart at graduation by every medical student. This definition was chosen because it parallels the item writers' instructions. The aim of our study was to answer the following questions:

1 Is core knowledge as intended by item writers considered core knowledge by postgraduate trainees and experienced specialists?

2 Do postgraduate trainees judge differently on core knowledge than experienced specialists?

3 Are experienced specialists and specialists in training biased towards their own specialty in the judgement of core knowledge? We used a sample of items from a newly introduced progress test at University Medical Centre Utrecht to conduct the study. 


\section{METHODS}

\section{Participants}

We approached the UMC Utrecht directors of postgraduate programmes of the 10 clinical specialties represented in the progress test. They were asked to provide the names and addresses of their postgraduate trainees. Nine directors provided these or chose to participate by distributing a questionnaire without revealing their postgraduate trainees' names; ophthalmology postgraduate trainees were not represented. Postgraduates therefore represented 9 different specialties; 297 postgraduate trainees were approached by letter or e-mail.

A total of 270 medical specialists with a teaching obligation in the medical curriculum were approached to participate in the study.

\section{Materials}

In 2002, a new progress test was introduced at UMC Utrecht School of Medical Sciences. ${ }^{14}$ Three times per year, Year 4 and 5 medical students sit a test, consisting of 40 short case descriptions, each followed by 1-3 short-answer clinical questions and 1-3 short-answer basic science questions. The test focuses on a wide range of clinical and basic science disciplines. Item writers are instructed to write questions that represent core knowledge, defined as "knowledge every graduating doctor should have immediately available without reference to written materials or consultations of others'. All items are reviewed in 2 stages by a small committee and a plenary test committee and most items are adapted before they are entered into the progress test.

For this study, 20 cases were selected from 2 different progress tests, 11 from 1 progress test and 9 from another. For each clinical discipline 2 cases were selected. The cases were chosen to represent a maximum distribution over the basic science disciplines. The selected cases covered all 10 different clinical disciplines and 6 different basic science disciplines: pathology (2), physiological chemistry (5), anatomy (4), immunology (1), physiology (5) and cell biology (3).

Each case included 1-3 clinical questions and 1-3 basic science questions. This resulted in 42 clinical questions and 38 basic science questions. Respondents were not asked to give the answer to the questions, but rather to rate each question on a 4-point scale with the following values:

1 = recently graduated medical students do not need to know the answer to this question;

2 = recently graduated medical students should be able to answer this quickly after referring to written materials;

3 = recently graduated medical students should be able to answer this after only a brief period of reasoning, and

4 = recently graduated medical students should be able to answer this immediately.

Categories 1 and 2 represented 'non-core knowledge', while categories 3 and 4 represented 'core knowledge', in the sense that it was to be assessed by the progress test.

\section{Procedure}

The postgraduate trainees were sent the questionnaire with a return envelope or return address in September 2003; the medical specialists received theirs in November 2003. For postgraduate trainees, an incentive (book token) was available for every fifth completed questionnaire. After 4 weeks, reminders were sent to both groups.

\section{Analysis}

In total, 150 participants responded to 80 questions. Questions left blank were excluded from the analysis (specialists $4.48 \%$; postgraduates $0.79 \%$ ). Three experienced specialists only responded to those questions that were related to their own specialty. In 19 cases $(0.16 \%)$ participants indicated 2 different answers. Here, the lowest indicated answer was used.

For each participant a mean score (range 1-4) was calculated over all the questions, as well as over the clinical questions and the basic science questions separately.

Results were analysed by a $2 \times 2$ analysis of variance (ANOVA) with postgraduate trainees and experienced specialists as the between-subjects factor and type of question (clinical and basic science) as the withinsubjects factor. For each question, means were calculated for postgraduates and specialists and a Pearson correlation was calculated to compare postgraduates and specialists over all questions.

Next, the scale was dichotomised into 'considered non-core knowledge' (values 1-2) and 'considered 
core knowledge' (values 3-4). A core knowledge percentage (how many times the answer was 3-4 divided by the total of filled in answers) was then calculated separately for the clinical and the basic science questions.

Finally, for each participant, a mean was calculated for his or her own specialty and a mean for the other disciplines. Means were based on the clinical questions. Eight participants were excluded because their specialty was unknown or the rating could not be calculated because too many items had been left blank. With the 10 specialties as between-subjects factor and their own specialty or other specialties as within-subjects factor, means were analysed using a $2 \times 10$ ANOVA.

\section{RESULTS}

In total, 150 respondents participated in the study. A total of 84 postgraduates returned the questionnaire (28.2\%; 33 male, 50 female, 1 anonymous). Their average age was 30.6 years (SD 3.62) and their average professional experience 3.2 years (SD 2.24). A total of 66 medical specialists participated (24.4\%; 48 male, 17 female, 1 anonymous). On average, their age was 47.8 years (SD 7.21) and their professional experience 21.4 years (SD 7.38).

\section{Is intended core knowledge by item writers judged to be core knowledge by both groups?}

The total number of judgements given was 11710 . When dichotomising the data, on average $63.4 \%$ of the items were rated with a 3 or 4 , indicating that only about 2-thirds of the questions were considered core knowledge. A $2 \times 2$ ANOvA showed a significant main effect of type of question (basic science or clinical $)(F(1,148)=900.643, P<0.001)$. On average, clinical questions were rated 3.29 (SD 0.32) by specialists and 3.22 (SD 0.28 ) by postgraduates. Basic science questions were rated 2.36 (SD 0.43) by experienced specialists and 2.43 (SD 0.36) by postgraduate trainees. Calculated differently, $82.4 \%$ of the clinical and $42.4 \%$ of the basic science items were considered to reflect core knowledge. Table 1 shows the distribution over the different answer options.

\section{Do postgraduate trainees judge core knowledge differently to experienced specialists?}

Postgraduates and medical specialists judged similarly on most questions. ANOva showed no significant main effect of group $(F(1,148)=0.006, P=0.941)$. In fact, there was a strong correlation $(r=0.975$, $P=0.01)$ between the mean scores per question of each group, indicating that postgraduate trainees and experienced specialists, as groups, almost perfectly agreed on most items. Figure 1 displays the means of specialists and postgraduate trainees for each question.

\section{Are specialists and postgraduate trainees biased towards their own specialties?}

Figure 2 shows the mean rating of specialists and postgraduate trainees on questions in their own specialty and questions in all other specialties. We used only the 42 clinical items, as we had no basic science respondents. A main effect of the participants' specialty was found $(\mathrm{F}(9,132)=4.856$, $P<0.001)$, indicating that different specialists judge differently (e.g. surgeons consider more questions to reflect core knowledge than paediatricians). However, no main effect of rating their own versus other specialties was found $(\mathrm{F}(1,140)=3.711, P=0.056)$, although a trend reflecting a bias towards the own specialty was visible.

\section{DISCUSSION}

The results of the study indicate that many test items designed by item writers to assess medical core

Table 1 Judgements of 150 respondents on 80 items constructed to test core knowledge

$\begin{array}{lccc}\text { Recently graduated medical students... } & \begin{array}{l}\text { All items } \\ (\boldsymbol{n}=\mathbf{8 0})\end{array} & \begin{array}{l}\text { Basic science items } \\ (\boldsymbol{n}=\mathbf{3 8})\end{array} & \begin{array}{r}\text { Clinical items } \\ (\boldsymbol{n}=\mathbf{4 2})\end{array} \\ \begin{array}{l}\text { 1 do not need to know this } \\ \text { 2 must be able to answer this quickly after }\end{array} & 29.2 \% & 43.7 \% & 1.7 \% \\ \quad \text { referring to written sources } & 34.2 \% & 30.7 \% & 37.9 \% \\ 3 \text { must be able to answer this after reasoning } & 29.2 \% & 11.7 & 45.1 \% \\ 4 \text { must be able to answer this immediately } & & \end{array}$




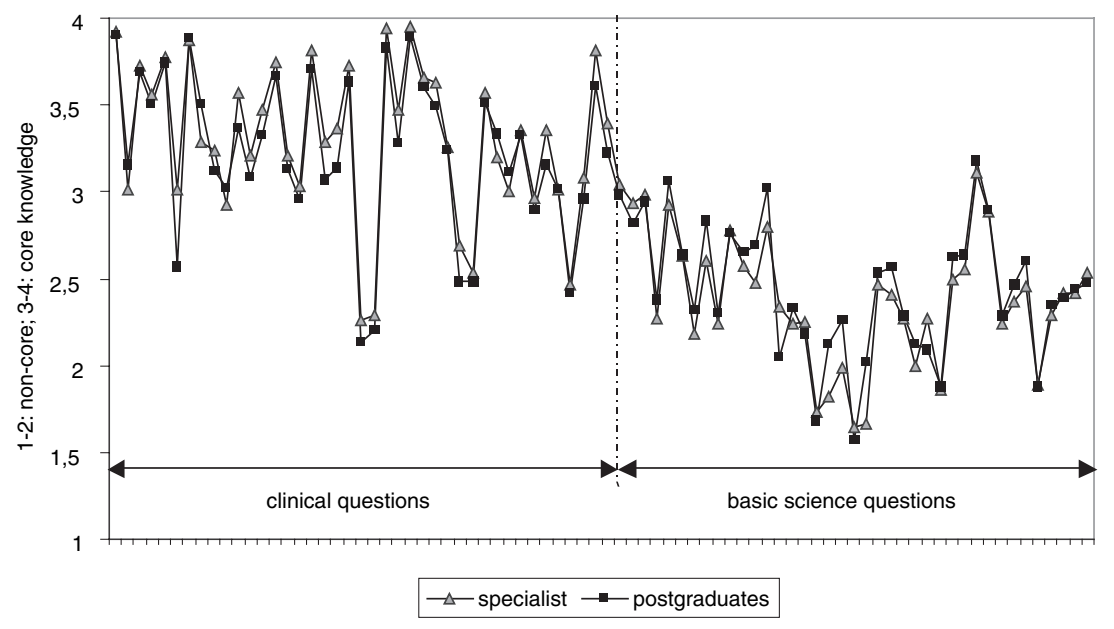

Figure 1 Average score per question by postgraduates and medical specialists.

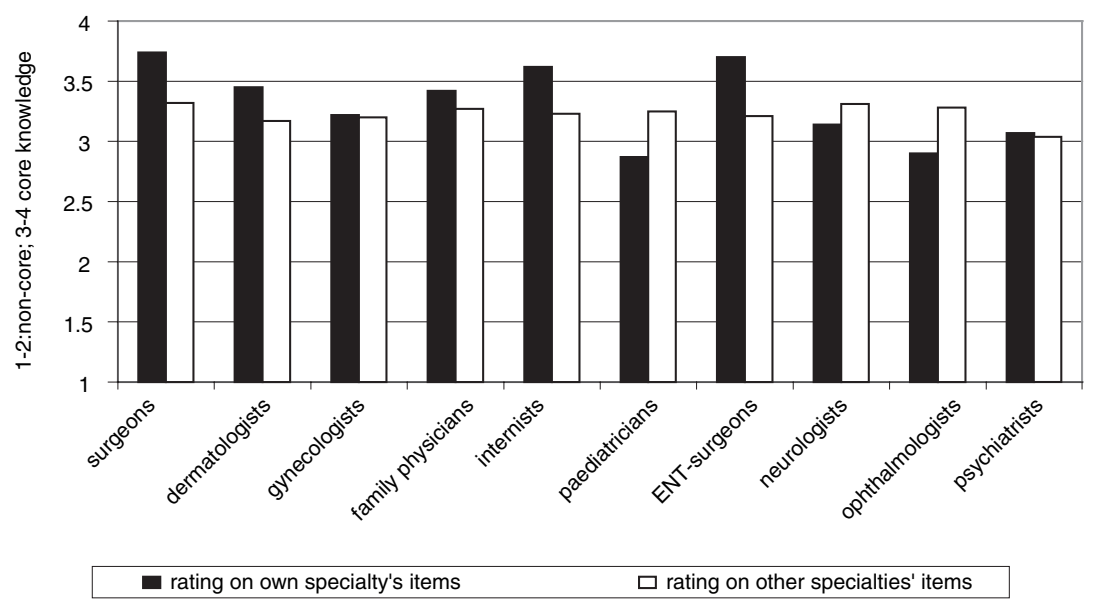

Figure 2 Mean rating of respondents on own specialties' and other specialties' items.

knowledge tend to be judged as reflecting non-core knowledge when judged by postgraduate trainees and experienced medical specialists. This holds especially for basic science questions. Interestingly, there appears to be almost perfect agreement between postgraduates and specialists on mean item level. We could not substantiate the possibility that participants rate their own specialties' items as reflecting core knowledge to a greater degree than those of other specialties, although a slight trend in this direction was visible among most specialties. Although the response rates were quite low, we think they were representative of the postgraduates and specialists because there was still a good representation of specialties. However, it is possible that the respondents who did participate felt more involved in teaching and were possibly more strict than other postgraduate trainees and specialists.
The finding that clinicians may regard basic science items as less relevant to medical training than basic scientists concords with earlier results. In a previous study regarding the required knowledge level of medical graduates, we found that basic science teachers in comparison with clinical teachers more often considered that a deep level of basic science knowledge (e.g. cellular or molecular) should be included in the curriculum. ${ }^{11}$ As basic scientists designed the basic science questions in our study, these questions may have assessed a level of knowledge that was too deep in the eyes of our respondents. Verhoeven et al. noted a similar discrepancy of opinion between item writers and postgraduate trainees. ${ }^{12}$ Now it appears that experienced specialists also show this discrepancy.

We have noticed that basic science teachers have difficulty in determining clinically relevant core 
knowledge. Not being clinicians themselves, we found that they tend to refer to the teaching programme (e.g. 'this has been explained extensively, and therefore should belong to the core knowledge of our students') rather than to clinical relevance. They may also consider 'core knowledge' from their own research expertise, which may be quite different to that from the clinical perspective. Conversely, clinicians may not actively use some of the basic science knowledge they acquired at earlier stages. Cognitive psychology studies have shown that medical experts use fewer pathophysiological concepts in explaining signs and symptoms of patients than do advanced medical students. They are thought to have encapsulated these concepts into their clinical knowledge. ${ }^{15}$ If this encapsulation reaches a level of subconsciousness, basic science concepts may seem less important to the expert than they really are. Contrary to this notion, however, is the striking similarity between the judgements of rather recently graduated doctors and those of specialists with an average clinical experience of over 20 years.

The general overestimation of core knowledge in students by item writers was reflected in the rather low scores students attained in the progress tests. In fact, Year 4 students taking the 2 tests used in this study achieved average scores of $44 \%$ and $48 \%$ on each test, respectively. The interpretation of these figures is not yet fully clear. At Maastricht Medical School, medical students showed an average score of $58 \%$ on a progress test at the end of 6 years of medical school, which may also be considered as rather low, as all items are considered to reflect relevant knowledge for all basic medical doctors. ${ }^{16}$ This finding was generally replicated in other medical schools in the Netherlands. ${ }^{17}$

Our last research question concerned whether participants would rate questions in their specialty as more reflective of core knowledge than those in other specialties. We found no differences, but a nonsignificant trend was visible, possibly indicating that in some disciplines experts may consider items from within their own specialty to be more reflective of core knowledge than items from other disciplines. Further investigation is necessary to substantiate such an effect.

The response rate for the study was rather small, possibly because answering the questionnaire was thought to take too much time. This might have somewhat influenced the representativeness of the results. However, the range of disciplines was as intended (except for 1 of 10 specialties among the postgraduates). Moreover, the response rate was roughly equal among postgraduates and specialists, which makes a comparison between these groups valid. It is possible that non-respondents would have answered the questionnaire differently and we can only speculate about the direction of their opinions. If the clinicians who responded were those who felt most involved with medical education and testing knowledge, which is not unlikely, they may have had a better picture of the content of the medical programme and current educational objectives than did the non-respondents. A more representative sample of respondents might then have yielded an even stronger effect in the direction we found, but again, this is only speculation.

Contributors: FK, JR and OTC were responsible for the initial design of the study. FK and JR designed the questionnaire. FK analysed the data. All authors contributed to editing and writing the manuscript. Acknowledgements: The authors would like to thank all the postgraduate trainees and experienced specialists who participated in this study.

Funding: none.

Conflicts of interest: none.

Ethical approval: authors state ethical approval not required.

\section{REFERENCES}

1 Brownell Anderson M, ed. Medical School Objectives Project. Report I. Learning Objectives for Medical Student Education. Guidelines for Medical Schools. Washington: Association of American Medical Colleges 1998. http://www.aamc. org/meded/msop/msop1.pdf.

2 General Medical Council. Tomorrow's Doctors. Recommendations on Undergraduate Medical Education. London: GMC 2003. http://www.gmc-uk.org/med_ed/ tomdoc.pdf.

3 Metz JCM, Verbeek-Weel AMM, Huisjes HJ. Blueprint 2001: Training of doctors in the Netherlands. Adjusted Objectives of Undergraduate Medical Education. Nijmegen: Universitair Publicatiebureau 2001.

4 Royal College of Physicians and Surgeons of Canada. Canadian Medical Education Directives for Specialists. Ottawa: RCPSC 2000. http:/ /www.rcpsc.medical.org.

5 Accreditation Council for Graduate Medical Education. Outcome Project. Chicago: ACGME Year. http:// www.acgme.org.

6 Bleker OP, Ten Cate TJ, Holdrinet RSG. General competencies of the future medical specialist. [In Dutch.] Dutch J Med Educ 2004;23 (1):4-14.

7 Harden RM, Davis MH. AMEE Medical Education Guide 5. The core curriculum with options or special study modules. Med Teach 1995;17 (2):125-49. 
8 Harden RM. The core curriculum. In: Dent JA, Harden RM, eds. A Practical Guide for Medical Teachers. London: Harcourt Publishers 2001.

9 Karle H, Adams O, Bajaj J, Baron-Maldonado M, Cravioto A, Dal Poz M, Geffen L, Hijazi S, Human D, Onur Ö et al. Basic Medical Education. WFME Global Standards for Quality Improvement. Copenhagen: WFME 2003. http://www.sund.ku.dk/wfme/Activities.

10 Dawson-Saunders B, Feltovich PJ, Coulson RL, Steward DE. A survey of medical school teachers to identify basic biomedical concepts medical students should understand. Acad Med 1990;65:448-54.

11 Koens F, Custers EJFM, Ten Cate TJ. Clinical and basic science teachers' opinions about the required depth of biomedical knowledge for medical students. Med Teach 2005; (in press).

12 Verhoeven BH, Verwijnen GM, Muijtjens AMM, Scherpbier AJJA, van der Vleuten CPM. Panel expertise for an Angoff standard setting procedure in progress testing. Item writers compared to recently graduated students. Med Educ 2002;36:860-7.

13 Harris JA, Heneghan HC, McKay DW. The rating of pre-clerkship examination questions by postgraduate medical students: an assessment of quality and relevancy to medical practice. Med Educ 2003;37:105-9.

14 Rademakers J, Ten Cate TJ, Bär PR. Progress testing with short answer questions. Med Teach 2005; (in press).

15 Van der Wiel, MWJ. Knowledge encapsulation. (PhD Thesis.) Maastricht University 1997.

16 Verhoeven BH, Verwijnen GM, Scherpbier AJ, van der Vleuten CP. Growth of medical knowledge. Med Educ 2002;36 (8):711-7.

17 Verhoeven BH, Verwijnen GM, Scherpbier AJJA et al. An analysis of progress test results of PBL and non-PBL students. Med Teach 1998;20 (4):310-6.

Received 4 June 2004; editorial comments to authors 14 July 2004; accepted for publication 12 October 2004 